\title{
Fitossociologia de plantas daninhas na cultura do milho submetida à aplicação de doses de nitrogênio
}

\section{Evander Alves Ferreira', Maria Carolina Gomes Paiva², Gustavo Antônio Mendes Pereira², Maxwel Coura Oliveira ${ }^{3}$, Enilson de Barros Silva ${ }^{1}$}

\author{
${ }^{1}$ Universidade Federal dos Vales do Jequitinhonha e Mucuri, Alto da Jacuba, Diamantina, Minas Gerais, Brasil. E-mail: \\ evanderalves@gmail.com, enilson.barros.silva@gmail.com \\ ${ }^{2}$ Universidade Federal de Viçosa, Campus Viçosa, Viçosa, Minas Gerais, Brasil. E-mail: maria.c.paiva@ufv.br, \\ gustavogamp@hotmail.com
}

${ }^{3}$ Universidade de Wisconsin-Madison, Main Campus, Madison, Estados Unidos. E-mail: maxwelco@gmail.com

Recebido: 20/05/2018; Aceito: 08/02/2019.

\begin{abstract}
RESUMO
O nitrogênio aplicado às culturas pode alterar o comportamento das plantas daninhas. Assim, algumas espécies são favorecidas pela presença de adubos nitrogenados em doses elevadas, e outras se mostram indiferentes. A finalidade deste estudo foi verificar os efeitos de diferentes doses de nitrogênio na dinâmica de plantas daninhas da lavoura durante o ciclo da cultura do milho. Foi testada a influência de doses de nitrogênio sobre o crescimento do híbrido de milho AG8088 YGRR e na dinâmica das plantas daninhas. A comunidade de espécies infestantes da lavoura sofreu alterações na sua dinâmica em função do tempo de amostragem e inserção de técnicas de plantio, assim como o aumento da disponibilidade de nitrogênio na área. A similaridade foi menor quando se aplicou menores doses de nitrogênio $\left(\mathrm{kg} \mathrm{ha}^{-1}\right)$ e a testemunha antes do plantio.
\end{abstract}

Palavras-chave: Adubação, AG8088 YGRR, Nitrogênio, Zea mays.

\section{Phytosociology of weed plants in corn crop submitted to application of nitrogen fertilizer rates}

\begin{abstract}
Nitrogen applied to crops may alter weed behavior. Thus, some species are favored by the presence of nitrogen fertilizers in high doses, and others are indifferent. The purpose of this study was to verify the effects of different nitrogen doses on the weed dynamics of the crop during the corn crop cycle. Nitrogen rates on the growth of the AG8088 YGRR corn hybrid and on weed dynamics were tested. The weed species community underwent alterations in their capacity of sampling and insertion of planting techniques; as well as increasing the availability of nitrogen in the area. The similarity was lower among the nitrogen doses $\left(\mathrm{kg} \mathrm{ha}^{-1}\right)$ and the control before planting.
\end{abstract}

Keywords: Fertilizing, AG8088 YG RR, Nitrogen, Zea mays. 
As plantas de milho estão sujeitas a fatores bióticos e abióticos, que interferem na sua produtividade final. Dentre os fatores bióticos, destaca-se a interferência negativa de plantas daninhas na cultura, seja na ausência ou na ineficiência de controle.

Assim, segundo Roesch et al. (2006), uma forma de assegurar a produtividade não só do milho, mas da maioria das plantas cultivadas, tem sido a utilização de quantidades substanciais de fertilizantes nitrogenados. $\mathrm{O}$ nitrogênio $(\mathrm{N})$ é um dos principais nutrientes exigidos pela cultura do milho, visto que esta necessita incorporar cerca de $25 \mathrm{~kg} \mathrm{ha}^{-1}$ de $\mathrm{N}$ para produzir uma tonelada de grãos (Pauletti, 1998).

Na maioria dos casos de competição entre a cultura do milho e as plantas daninhas, o $\mathrm{N}$ é o primeiro nutriente a ser limitante (Balbinot Junior et al., 2009). O nitrogênio aplicado às culturas pode alterar o comportamento das plantas daninhas. Algumas espécies são favorecidas pela presença de adubos nitrogenados em doses elevadas, e outras se mostram indiferentes (Moss et al., 2004).

De acordo com Concenço et al. (2013), o estudo fitossociológico, em termos simples, é um grupo de métodos de avaliações ecológicas, cujo objetivo é proporcionar uma visão abrangente da composição e distribuição de espécies de plantas em uma comunidade vegetal. Estes métodos foram originalmente desenvolvidos para descrever as espécies vegetais presentes em uma área (Guglieri-Caporal et al., 2010), assumindo um papel importante para a ciência das plantas daninhas.

O progresso dos estudos fitossociológicos vem acontecendo de forma lenta e não sincronizada nos diferentes grupos de pesquisa do país. De modo geral, um dos motivos principais dessa diferença deve-se ao baixo número de pesquisadores atuando nessa área, nas diferentes regiões do Brasil (Giehl e Budke, 2011).

Segundo Cruz et al. (2009), é importante e necessária a identificação das espécies de plantas daninhas, pois cada uma apresenta potencial de estabelecer-se na área e sua agressividade pode interferir de forma diferenciada entre as culturas. Assim como os mesmos autores afirmam que os índices fitosssociológicos são importantes para analisar o impacto que os sistemas de manejo e as práticas agrícolas exercem sobre a dinâmica de crescimento e ocupação de comunidades infestantes em agroecossistemas.

A realização de estudos fitossociológicos permite avaliar a composição das espécies da vegetação de cobertura, obtendo-se frequência, frequência relativa, densidade, densidade relativa, abundância, abundância relativa e índice de importância relativa, sendo uma importante ferramenta utilizada na inferência sobre a comunidade em questão (Gomes et al., 2010).
Outro parâmetro utilizado é o índice de similaridade de Sorensen (Sorensen, 1972), o qual se baseia na presença ou ausência das espécies. As espécies comuns entre duas amostras, quando comparadas, recebem um peso maior do que aquelas que são exclusivas a uma ou outra amostra.

Do ponto de vista agronômico, o conhecimento da diversidade de espécies é importante para o entendimento da dinâmica das plantas daninhas em relação às plantas cultivadas, nas diferentes épocas de cultivo. Apesar dessa importância, há carência dessas informações para regiões produtoras (Albuquerque et al., 2012).

A identificação de espécies infestantes é importante, pois os prejuízos ocasionados pela competição dependem das espécies envolvidas, da densidade de populações e do seu estádio de desenvolvimento. As comunidades infestantes podem ainda variar sua composição florística em função do tipo e da intensidade dos tratos culturais, tornando indispensável o reconhecimento das espécies presentes e o investimento em métodos que ajudem no conhecimento dessas comunidades (Nordi e Landgraf, 2009).

A hipótese desta pesquisa é de que há variação na composição das espécies vegetais infestantes, com a inserção de práticas agrícolas e o período de cultivo da cultura. Nesse contexto, a finalidade deste estudo foi verificar os efeitos de diferentes doses de nitrogênio na dinâmica de plantas daninhas da lavoura durante o ciclo da cultura do milho.

O experimento foi conduzido na Estação Experimental de Rio Manso, pertencente à Universidade Federal dos Vales do Jequitinhonha e Mucuri, localizada no município de Couto de Magalhães de Minas-MG. A área utilizada se constitui em um Latossolo Vermelho-amarelo distrófico de textura argilosa (24\% de argila, $11 \%$ de silte e $64 \%$ de areia). A análise química do solo apresentou $\mathrm{pH}$ (água) de 6,0; teor de matéria orgânica de $0,9 \mathrm{dag} \mathrm{\textrm {kg } ^ { - 1 }} ; \mathrm{P}, \mathrm{K}, \mathrm{Ca}, \mathrm{Mg}$, $\mathrm{Al}, \mathrm{H}+\mathrm{Al}$ e $\mathrm{CTC}_{\text {efetiva }}$ de 1,$66 ; 56,5 ; 1,30 ; 0,40 ; 0,14$; 2,10; e $1,98 \mathrm{cmol}_{\mathrm{c}} \mathrm{dm}^{-3}$, respectivamente. A adubação foi realizada de acordo com a recomendação para a cultura do milho (Alvarez et al., 1999), sendo aplicado $150 \mathrm{~kg} \mathrm{ha}^{-1}$ de $\mathrm{P}$ e $100 \mathrm{~kg} \mathrm{ha}^{-1}$ de $\mathrm{K}$ após a aração do terreno.

Para o plantio das sementes, o híbrido de milho utilizado na pesquisa foi AG8088 YGRR, sendo adotado espaçamento $0,9 \mathrm{~m}$ entre linhas, com sete sementes/metro linear.

O delineamento utilizado foi de blocos ao acaso com quatro repetições e cinco tratamentos constituídos de diferentes doses de $\mathrm{N}$ em cobertura $\left(\mathrm{kg} \mathrm{ha}^{-1}\right)$ : 0, 70, 140, 210 e 420, na forma de sulfato de amônio, que contém $21 \%$ de $\mathrm{N}$ aplicados no plantio e em cobertura. Foram realizadas duas aplicações em cobertura, aos 15 dias 
após a emergência (plantas de milho com quatro folhas) e aos 35 dias após a emergência da cultura (plantas de milho com 12 folhas). A dose de $\mathrm{N}$ aplicada foi semelhante nas três aplicações (plantio, $1^{\mathrm{a}}$ aplicação e $2^{\mathrm{a}}$ aplicação), sendo utilizado $1 / 3$ da dose em cada uma delas. As parcelas foram compostas por $2000 \mathrm{~m}^{2}$.

As avaliações fitossociológicas da flora emergente foram realizadas antes da implantação da cultura na área e após a aplicação da segunda dose de $\mathrm{N}$ no milho, 35 dias após a emergência. Para isso, utilizou-se o método do quadrado inventário, aplicado por meio de um quadrado de 1,0 $\mathrm{m}^{2}$, lançado ao acaso, em média, 10 vezes em cada parcela, calculando-se dessa forma a média por espécie nas parcelas avaliadas por tratamento. Após a coleta das plantas nas áreas, foram estimadas a frequência relativa (FRR), a densidade relativa (DER) e a abundância relativa (ABR) - que informam a relação de cada espécie com as outras encontradas na área; e o índice de valor de importância (IVI) - que indica quais espécies são mais importantes dentro da área estudada.

Os dados referentes à precipitação e temperaturas médias nos meses de setembro de 2014 a janeiro de 2015 estão representados na Figura 1.

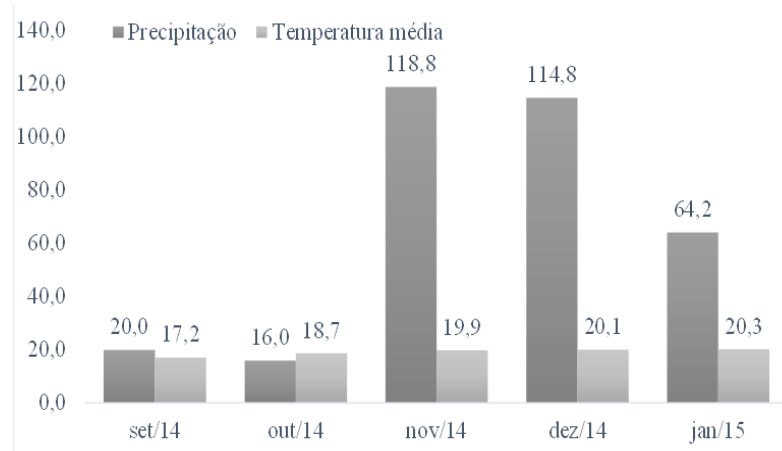

Figura 1. Precipitação $(\mathrm{mm})$ e temperaturas médias $\left({ }^{\circ} \mathrm{C}\right)$ nos meses de setembro de 2014 a janeiro de 2015. Couto de Magalhães de Minas - MG, Estação Experimental de Rio Manso pertencente à Universidade Federal dos Vales do Jequitinhonha e Mucuri - UFVJM.

A classificação adotada tomou como base o sistema Angiosperm Phylogeny Group III (2009), com auxílio nas delimitações das famílias e ordenamento de alguns gêneros. Entretanto, na identificação e quantificação das espécies, também foi utilizada literatura específica (Lorenzi, 2008).

Frequência (Fre): é expressa em termos de percentagem de amostras em que os indivíduos de uma espécie foram detectados em relação ao número total de amostras efetuadas.

Frequência (Fre) $=\frac{\text { Número de parcelas que contém espécie }}{\text { Número total de parcelas utilizadas }}$

Frequência relativa (FER): foi determinada dividindo-se a frequência de uma espécie pela frequência de todas as espécies encontradas nas amostragens.

$$
\text { Frequência Relativa }(\mathrm{FER})=\frac{\text { Frequência da espécie } \times 100}{\text { Frequência total de todas as espécies }}
$$

Densidade (Den): refere-se ao número de espécie por unidade de área, expressa em plantas por $\mathrm{m}^{2}$.

$$
\text { Densidade }(\text { Den })=\frac{\text { Número total de indivíduos por espécie }}{\text { Área total coletada }}
$$

Densidade relativa (DER): foi determinada dividindo-se o número de indivíduos de uma determinada espécie encontrada nas amostragens pelo número total de indivíduos das espécies amostradas dentro da comunidade estudada.

Densidade Relativa $($ DER $)=\frac{\text { Densidade da espécie } \times 100}{\text { Densidade total de todas as espécies }}$

Abundância ( $\mathrm{Abu}$ ): informa sobre as espécies que ocorrem concentradas em determinados pontos.

$$
\text { Abundância }(\mathrm{Abu})=\frac{\text { Número total de indivíduos por espécie }}{\text { Número total de parcelas com a espécie }}
$$

Abundância relativa (ABR): é calculado em relação ao número total de indivíduos de todas as espécies existentes na área amostrada:

$$
\text { Abundância Relativa }(\mathrm{ABR})=\frac{\text { Abundância da espécie } \times 100}{\text { Abundância total de todas as espécies }}
$$

Índice do valor de importância (IVI): é calculado pela somatória da densidade relativa mais a frequência relativa mais a dominância relativa de cada população.

\section{Indice de Valor de importância(IVI) $=\mathrm{Frr}+\mathrm{Der}+\mathrm{Abr}$}

Ao final, estabeleceu-se a comparação entre as áreas por meio do índice de similaridade (IS). Para avaliação da similaridade entre as populações botânicas nas áreas estudadas foi utilizado o IS - Índice de Similaridade de Sorensen (Sorensen, 1972) por meio da fórmula: IS (\%) $=(2 \mathrm{a} / \mathrm{b}+\mathrm{c})^{*} 100$, em que $\mathrm{a}=$ número de espécies comuns às duas áreas; e b e c = número total de espécies nas duas áreas comparadas. O IS varia de 0 a 100, sendo máximo quando todas as espécies são comuns às duas áreas e mínimo quando não existem espécies em comum.

A classificação adotada tomou como base o sistema Angiosperm Phylogeny Group III (2009), com auxílio nas delimitações das famílias e ordenamento de alguns gêneros, conforme Lorenzi (2008) e Lorenzi (2014), além de bibliografias sobre plantas medicinais, ornamentais, dissertações e teses relacionadas ao assunto.

Foram observadas no experimento 24 espécies de plantas daninhas distribuídas em 10 famílias botânicas, nos diferentes tratamentos analisados. Em termos de diversidade de espécies, as Eudicotiledôneas 
predominaram na composição da comunidade daninha com $75 \%$, enquanto as monocotiledôneas apresentaram $25 \%$ de participação; foram encontradas na área do experimento seis espécies de metabolismo $\mathrm{C} 4$, sendo a grande maioria classifica como C3. As famílias mais observadas na área foram Poaceae, Asteraceae e Fabaceae (Tabela 1).

As famílias encontradas na área experimental desse trabalho assemelharam-se às identificadas por Benedetti et al. (2009) na cultura da soja, dentre as quais também se destacaram Poaceae e Asteraceae, ambas com quatro espécies. Esses resultados também corroboram as pesquisas realizadas por Marques et al. (2010) na cultura do feijão-caupi, e Cardoso et al. (2013) na cultura da mandioca, nas quais relatam que, entre as famílias identificadas, Asteraceae foi detentora de grande número de espécies. Maciel et al. (2010), ao realizarem um levantamento fitossociológico em um cafezal orgânico, também encontraram resultados semelhantes em relação à família Poaceae. Oliveira e Freitas (2008) consideram as famílias Poaceae e Asteraceae como as principais famílias de plantas daninhas existentes no Brasil. Segundo Lorenzi (2008), grande parte das espécies das famílias Poaceae e Asteraceae produz grande quantidade de diásporos, o que facilita a disseminação e a ocupação do nicho ecológico em diversos ambientes, mesmo sob condições consideradas desfavoráveis ao crescimento vegetal.

$\mathrm{Na}$ avaliação realizada antes do plantio do milho, observou-se que as espécies com maior densidade relativa (DER) foram D. teres, $C$. echinatus e $P$. teneriffae. Em relação à frequência relativa (FER), verificou-se que as espécies $D$. teres, $C$. echinatus e $A$. australe mostraram maiores valores referentes a esse índice. D. teres, $C$. echinatus e $P$. teneriffae apresentaram maiores valores de abundância relativa $(A B R)$ e índice de valor de importância (IVI) (Figura 2A).

Tabela 1 - Nomes científicos, nomes comuns, famílias e classes botânicas das 24 espécies coletadas de plantas daninhas.

\begin{tabular}{|c|c|c|c|c|}
\hline Família & & Nomes Científicos & $\begin{array}{l}\text { Nome Comum (tipo de } \\
\text { metabolismo fotossintético) }\end{array}$ & Classe \\
\hline Amaranthaceae & 1 & Alternanthera tenella & Apaga-fogo (C3) & Eudicotyledoneae \\
\hline Asteraceae & 2 & Acanthospermum australe & Carrapichinho (C3) & Eudicotyledoneae \\
\hline Asteraceae & 3 & Acanthospermum hispidum & Carrapicho-de-carneiro (C3) & Eudicotyledoneae \\
\hline Asteraceae & 4 & Bidens pilosa & Picão Preto (C3) & Eudicotyledoneae \\
\hline Asteraceae & 5 & Emilia fosbergii & Falsa-serralha (C3) & Eudicotyledoneae \\
\hline Asteraceae & 6 & Tagetes minuta & Cravo-de-defunto (C3) & Eudicotyledoneae \\
\hline Commelinaceae & 7 & Commelina benghalensis & Trapoeraba $(\mathrm{C} 4)$ & Monocotyledoneae \\
\hline Convolvulaceae & 8 & Ipomoea grandifolia & Corda-de-viola (C3) & Eudicotyledoneae \\
\hline Fabaceae & 9 & Aeschynomene denticulata & Angiquinho (C3) & Eudicotyledoneae \\
\hline Fabaceae & 10 & Arachis hypogaea & Amendoim (C3) & Eudicotyledoneae \\
\hline Fabaceae & 11 & Desmodium turtuosum & Carrapicho-beiço-de-boi (C3) & Eudicotyledoneae \\
\hline Fabaceae & 12 & Senna obtusifolia & Fedegoso (C3) & Eudicotyledoneae \\
\hline Malvaceae & 13 & Sida glaziovii. & Guaxuma-branca (C3) & Eudicotyledoneae \\
\hline Malvaceae & 14 & Sida rhombifolia & Guanxuma (C3) & Eudicotyledoneae \\
\hline Malvaceae & 15 & Sida urens & Guaxuma-dourada (C3) & Eudicotyledoneae \\
\hline Oxalidaceae & 16 & Oxalis latifólia & Trevo-azedo (C3) & Eudicotyledoneae \\
\hline Poaceae & 17 & Urochroa decumbens & Capim-braquiária (C4) & Monocotyledoneae \\
\hline Poaceae & 18 & Urochroa plantaginea & Capim-marmelada (C4) & Monocotyledoneae \\
\hline Poaceae & 19 & Cenchrus echinatus & Capim-carrapicho (C4) & Monocotyledoneae \\
\hline Poaceae & 20 & Eleusine indica & Capim-pé-de-galinha (C4) & Monocotyledoneae \\
\hline Poaceae & 21 & Panicum teneriffae & Capim-quicé (C4) & Monocotyledoneae \\
\hline Rubiaceae & 22 & Diodia tereswalt & Mata-pasto (C3) & Eudicotyledoneae \\
\hline Rubiaceae & 23 & Spermacoce latifolia & Erva-quente (C3) & Eudicotyledoneae \\
\hline Solanaceae & 24 & Solanum americanum & Maria-pretinha(C3) & Eudicotyledoneae \\
\hline
\end{tabular}


A elevada FER indica que D. teres ocorreu de forma uniforme e bem distribuída em toda área no período anterior ao plantio, constituindo-se, de forma geral, na espécie mais importante encontrada na área pelo seu elevado IVI. Segundo Lorenzi (2008), D. teres é uma espécie infestante, principalmente em pastagens, e por não ser palatável ao gado pode até dominar a gramínea, competindo com as culturas de algodão, feijão, frutíferas, fumo, mamona, milho, sorgo e culturas perenes. Essa espécie prefere solos arenosos, sobrevivendo a períodos de seca. Considerando que a primeira avaliação foi realizada antes do plantio do milho na área, no mês de setembro, ou seja, antes do início do período chuvoso, é esperada a presença de espécies mais tolerantes à seca, como as observadas no presente trabalho.

A

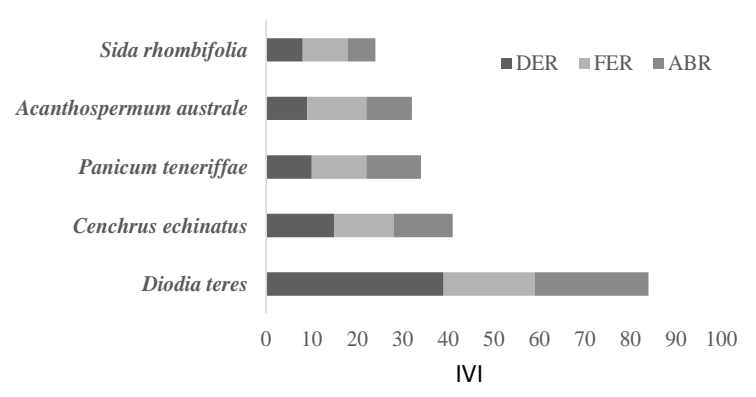

C

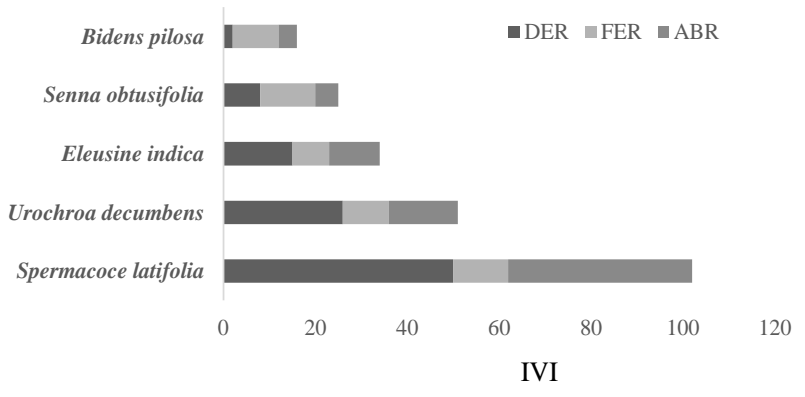

E

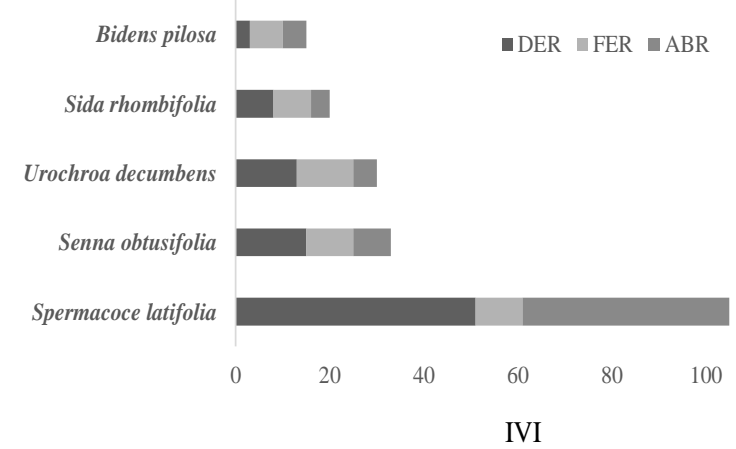

$\mathrm{Na}$ avaliação realizada após o plantio da cultura do milho, verificou-se variação na DER, FER, ABR e IVI das espécies encontradas na área do experimento em relação ao período anterior ao plantio, tanto nas áreas adubadas quanto na parcela que não recebeu adubação nitrogenada (Figuras 2 B a F). Essas alterações na comunidade de plantas daninhas se devem a mudanças climáticas, principalmente com o início do período chuvoso e a presença da cultura do milho na área, considerando que a primeira avaliação foi realizada antes do plantio do milho, no mês de setembro, ou seja, antes do início do período chuvoso e as parcelas plantadas foram avaliadas no final de dezembro, na ocasião da segunda adubação nitrogenada, com o predomínio de temperaturas mais elevadas e maiores índices de precipitação.

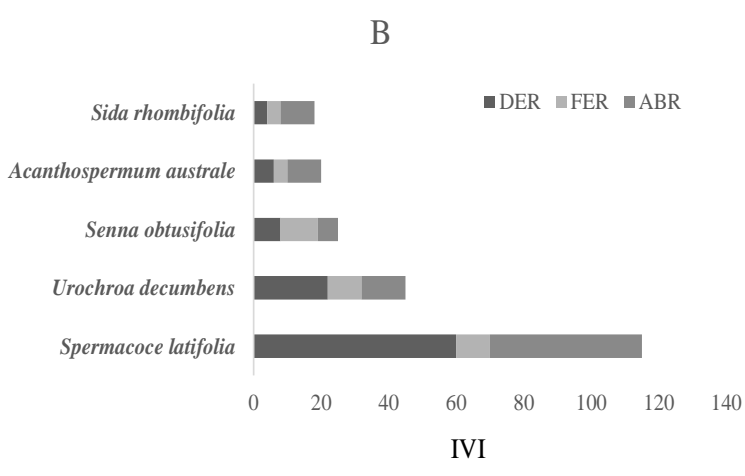

$\mathrm{D}$
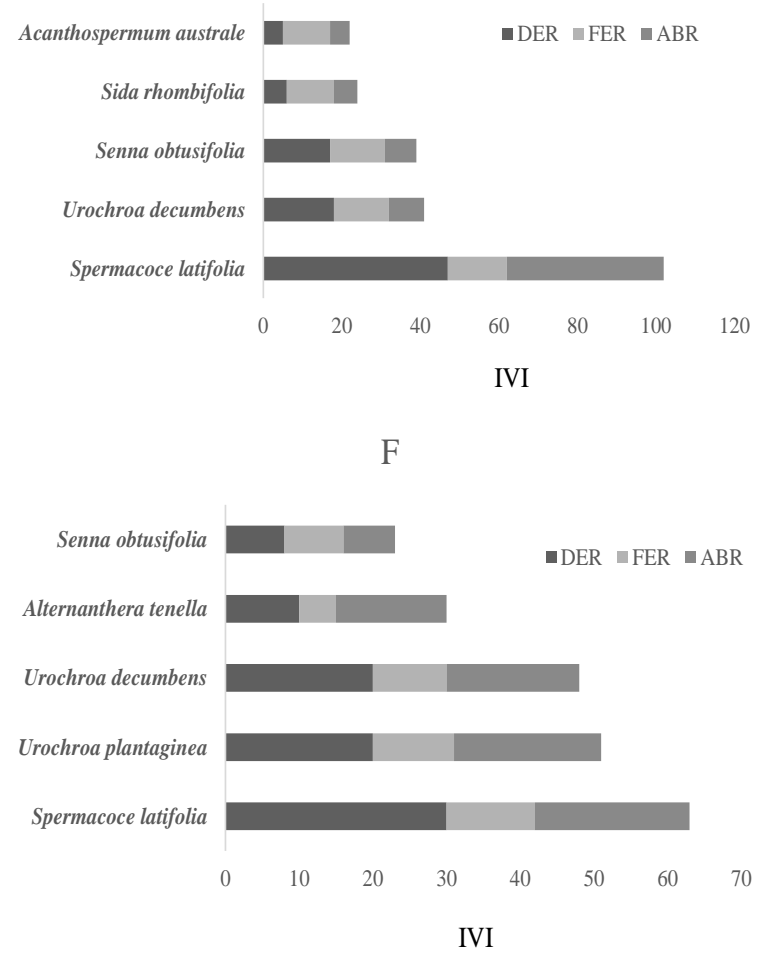

Figura 2. Densidade relativa (DER), Frequência relativa (FER), Abundância relativa (ABR) e Índice de Valor de Importância (IVI) da A) Avaliação anterior ao plantio; B) Milho cultivado na dose zero de nitrogênio; C) Milho cultivado na dose $70 \mathrm{~kg} \mathrm{ha}{ }^{-1} \mathrm{de} \mathrm{N}$; D) Milho cultivado na dose $140 \mathrm{~kg} \mathrm{ha}^{-1} \mathrm{de} \mathrm{N}$; E) Milho cultivado na dose $210 \mathrm{~kg} \mathrm{ha}^{-1}$ de N; F) Milho cultivado na dose $420 \mathrm{~kg} \mathrm{ha}^{-1} \mathrm{de} \mathrm{N}$. 
Um dos mecanismos para o sucesso de plantas daninhas que vem recebendo considerável atenção recentemente é a hipótese da "razão de recursos" (Harpole, 2006), que propõe que as plantas variam em suas necessidades nutricionais e que a maior disponibilidade de um nutriente pode beneficiar algumas plantas enquanto inibe outras através de interações competitivas (Wan et al., 2018).

Nas parcelas adubadas com 0,00, 70,00 e $140 \mathrm{~kg} \mathrm{ha}^{-1}$ de $\mathrm{N}$, as espécies $S$. latifolia e $U$. decumbens apresentaram os maiores valores de DER, FER, ABR e IVI (Figuras 2B, C e D). Dessa forma, essas espécies foram as mais importantes encontradas na lavoura de milho não adubada e nas parcelas que receberam até $140 \mathrm{~kg} \mathrm{ha}^{-1}$ de N.

S. latifolia apresenta reprodução por meio de sementes, com ciclo anual, podendo ser mais longo que o das culturas anuais de verão. Adapta-se a solos pobres a ácidos, porém seu desenvolvimento é maior em solos férteis. Devido à sua tolerância a sombreamento, compete com a cultura durante todo o ciclo, sendo encontrada mais comumente no verão, nas lavouras da região meridional do Brasil (Lorenzi, 2008). Considerando que essa espécie pode ocorrer tanto em solos pobres como em solos férteis, explica sua presença em parcelas sem adubação nitrogenada até nas parcelas com 70 e $140 \mathrm{~kg} \mathrm{ha}^{-1}$ de $\mathrm{N}$.

Em trabalho realizado por Oliveira et al. (2014), a adubação com NPK no milho em monocultivo capinado favoreceu o aumento da população de capim camalote (Rottboelia exaltata) e apaga-fogo (Alternanthera tenella), resultando, em ambos os casos, em IVI cinco vezes maior que o milho capinado, quando não recebeu a adubação com NPK.

Nas parcelas adubadas com $210 \mathrm{~kg} \mathrm{ha}^{-1}$ de $\mathrm{N}$, a espécie mais importante foi $S$. latifólia, seguida de $S$. obtusifolia e $U$. decumbens; essas espécies mostraram também os maiores valores de DER, FER e ABR (Figura 2E).

Concenço et al. (2013) sugerem que o controle de espécies abundantes deve ser, de preferência, em préemergência e para as espécies menos frequentes por práticas de manejo e, em pós-emergência, impedindo-as de acumular massa e dominar o campo. Isso porque espécies abundantes são amplamente distribuídas na área, portanto, o controle em pré-emergência iria desempenhar um papel importante na redução da sua ocorrência. Como espécies menos frequentes ocorrem em locais específicos do campo, em muitos casos, não haveria necessidade de aplicar um controle em toda a área. Portanto, é fundamental localizar as espécies no início da germinação para aplicar as práticas de controle.

S. latifólia foi também a espécie mais importante nas parcelas adubadas com $420 \mathrm{~kg} \mathrm{ha}^{-1} \mathrm{de} \mathrm{N}$, apresentando maiores valores de DER, FER, ABR, seguida pelas braquiárias $U$. plantaginea e $U$. decumbens (Figura $2 \mathrm{~F}$ ). Dessa forma, nas parcelas adubadas com $420 \mathrm{~kg} \mathrm{ha}^{-1} \mathrm{de}$ $\mathrm{N}$, verificou-se predominância de braquiárias, sendo as duas espécies encontradas caracterizadas pelo metabolismo fotossintético do tipo $\mathrm{C} 4$, sendo que essas espécies juntas mostraram maior importância na área.

Urochroa plantaginea, conhecida popularmente como capim papuã, apresenta ciclo anual e reprodução por sementes. Essa infestante se encontra distribuída na maioria dos sistemas de plantio, afetando diversas culturas agronômicas, sendo bastante disseminada nas regiões Sul, Centro-oeste e Sudeste do país (Lorenzi, 2008).

Conhecida popularmente como capim-braquiária, a espécie $U$. decumbens possui apenas a sinonímia botânica Brachiaria decumbens Stapf. Esta espécie, segundo a caracterização do Instituto Hórus (2018), é uma planta perene de crescimento subereto ou decumbente, atingindo de 30 a $100 \mathrm{~cm}$ de altura, cespitosa, rizomatosa, estolonífera, com enraizamento nos nós inferiores em contato com o solo. A morfologia é bem variável para esta espécie. $U$. decumbens apresenta metabolismo fotossintético do tipo $\mathrm{C} 4$, o que faz com que se desenvolva melhor em ambientes com elevada incidência luminosa. Ambientes ricos em recursos frequentemente apresentam maior invasão de plantas daninhas do que ambientes com poucos recursos, e espécies invasoras apresentam desempenho superior em ambientes ricos em recursos, possibilitando altas taxas de crescimento, reprodução precoce e muitos descendentes (Wan et al., 2018).

De forma geral, após o plantio do milho, observouse modificação na importância das espécies daninhas presentes na área (Figura 2 A a F). No estádio préplantio, D. teres se constituiu na espécie mais importante, no entanto, após o plantio das parcelas não adubadas e parcelas submetidas a doses crescentes de nitrogênio, a espécie mais importante foi $S$. latifolia. Segundo Ferreira et al. (2014), as mudanças entre sistemas de manejo do solo podem influenciar a germinação e o estabelecimento de plantas daninhas, devido à criação de condições variáveis de umidade e aeração.

Ao se avaliar o índice de similaridade (IS) entre os tratamentos, verificaram-se maiores diferenças entre a área antes do plantio do milho (testemunha) em relação às parcelas após o plantio da cultura, sendo que o IS entre a testemunha e as áreas cultivadas com milho sob diferentes doses de nitrogênio mostraram valores de IS variando de $35,7 \%$ (140 $\mathrm{kg} \mathrm{ha}^{-1}$ de $\mathrm{N}$ x Testemunha) a $58,06 \%$ (0,00 kg ha ${ }^{-1}$ de $\mathrm{N} x$ Testemunha) (Tabela 2).

Valores de IS superiores a $50 \%$ representam alta similaridade entre as parcelas avaliadas. Dessa forma, a comparação entre as parcelas avaliadas antes e após o 
plantio (com as diferentes doses de nitrogênio) pode ser considerada como baixa similaridade. Isso revela que as espécies encontradas antes e depois do plantio do milho são diferentes nas duas épocas, o que caracteriza uma mudança de população de plantas daninhas no tempo.

Maiores valores de IS foram observados nas parcelas tratadas com as maiores doses de $\mathrm{N}$, sendo $85,86 \%$ (210 $\mathrm{Kg}$ de N/ha x $140 \mathrm{Kg}$ de N/ha e $420 \mathrm{~kg} \mathrm{ha}^{-1}$ de N x 140 $\mathrm{kg} \mathrm{ha}^{-1}$ de N) e 93,75\% (420 kg ha-1 de N x $210 \mathrm{~kg} \mathrm{ha}^{-1}$ de N (Tabela 2).

Constatou-se uma mudança de população de plantas daninhas na área quando comparados os IS antes e depois do plantio do milho adubado com diferentes doses de nitrogênio, no entanto, essa mudança de espécies foi verificada também quando se compara as parcelas tratadas com as menores doses de nitrogênio com as que receberão as maiores dosagens. Nas maiores doses, a similaridade entre as parcelas foi de mais de $90 \%$, considerando as doses de $210 \mathrm{~kg} \mathrm{ha}^{-1}$ de $\mathrm{N}$ x 420 $\mathrm{kg} \mathrm{ha}{ }^{-1}$ de N. Segundo Tilman e Wedin (1991), a biomassa da cultura, bem como a biomassa das plantas daninhas aumentam e a composição da comunidade muda após a adição de $\mathrm{N}$; entretanto, esse efeito não é observado após a adição de $\mathrm{P}, \mathrm{K}, \mathrm{Ca}, \mathrm{Mg}, \mathrm{S}$.

Mi et al. (2018), trabalhando com doses crescentes de nitrogênio e seu efeito na comunidade de plantas daninhas, verificaram que o número de espécies foi significativamente influenciado pela fertilização. O maior número de espécies de plantas daninhas foi registrado no tratamento sem a presença do nitrogênio, seguido do tratamento onde o mesmo foi aplicado em alta dosagem $\left(300 \mathrm{~kg} \mathrm{ha}^{-1}\right.$ de $\left.\mathrm{N}\right)$.

Tabela 2 - Índice de similaridade (IS - \%) espécies de plantas daninhas catalogadas em área antes do preparo para plantio (Testemunha) e durante o cultivo de milho AG8088 YG RR, 39 dias após a emergência sob efeito das doses de nitrogênio, em kg ha${ }^{1}: 0,70,140,210$ e 420

\begin{tabular}{|c|c|c|c|c|c|}
\hline IS (\%) & Testemunha & $0 \mathrm{~kg} \mathrm{ha}^{-1}$ & $70 \mathrm{~kg} \mathrm{ha}^{-1}$ & $140 \mathrm{~kg} \mathrm{ha}^{-1}$ & $210 \mathrm{~kg} \mathrm{ha}^{-1}$ \\
\hline $0 \mathrm{~kg} \mathrm{ha}^{-1}$ & 58,06 & & & & \\
\hline $70 \mathrm{~kg} \mathrm{ha}^{-1}$ & 46,66 & 77,41 & & & \\
\hline $140 \mathrm{~kg} \mathrm{ha}^{-1}$ & 35,71 & 75,86 & 71,42 & & \\
\hline $210 \mathrm{~kg} \mathrm{ha}^{-1}$ & 51,61 & 77,50 & 77,41 & 85,86 & \\
\hline $420 \mathrm{~kg} \mathrm{ha}^{-1}$ & 51,61 & 77,50 & 77,41 & 85,86 & 93,75 \\
\hline
\end{tabular}

Antes do plantio do milho, a espécie mais importante na área foi $D$. teres. Durante o cultivo da cultura, destacou-se a espécie $S$. latifolia nas parcelas sem adubação e nas parcelas com doses crescentes de nitrogênio.

A similaridade entre plantas é maior nas parcelas entre as doses de $\mathrm{N}$ do que a comparação antes e após o preparo da área de plantio do milho.

\section{Agradecimentos}

Os autores agradecem ao CNPq, à FAPEMIG e à CAPES pelas bolsas e apoio financeiro concedido.

\section{Referências Bibliográficas}

Albuquerque, J.A.A., Melo, V.F., Siqueira, R.H.S., Martins, S.A., Finoto, E.L., Sediyama, T., Silva, A.A., 2012. Ocorrência de plantas daninhas após cultivo de milho na savana amazônica. Planta Daninha, 30(4), 775-782.

Alvarez, V.V.H., Novais, R.F., Barros, N.F., Cantarutti, R.B., Lopes, A.S., 1999. Interpretação dos resultados das análises de solos, in: Ribeiro, A.C., Guimarães, P.T.G., Alvarez, V.V.H., (Ed.), Recomendação para o uso de corretivos e fertilizantes em Minas Gerais: $5^{\text {a }}$ Aproximação. Viçosa, Comissão de Fertilidade do Solo do Estado de Minas Gerais, p. 25-32.
Angiosperm Phylogeny Group, 2009. An update of the Angiosperm Phylogeny Group classification for the orders and families of flowering plants: APG II Botanical Journal of the Linnean Society, 141, 399-436.

Balbinot Junior, A.A., Moraes, A., Veiga, M., Pelissari, A., Dieckow, J., Carvalho, P.C.F., 2009. Desempenho da cultura do feijão após diferentes formas de uso do solo no inverno. Ciência Rural, 39(8), 2340-2346.

Benedetti, J.G.R., Pereira, L., Alves, P.L.C.A., Yamauti, M.S., 2009. Período anterior à interferência de plantas daninhas em soja transgênica. Scientia Agraria, 10(4), 289-295.

Cardoso, A.D., Viana, A.E.S., Barbosa, R.P., Teixeira, P.R.G., Cardoso Júnior, N.S., Fogaça, J.J.N.L., 2013. Levantamento fitossociológico de plantas daninhas na cultura da mandioca em Vitória da Conquista, Bahia. Biosci. J., 29(5), 1130-1140.

Concenço, G., Tomazi, M., Correia, I.V.T., Santos, S.A., Galon, L., 2013. Phytosociological surveys: tools for weedscience? Planta Daninha, 31(2), 469-482.

Cruz, D.L.S., Rodrigues, G.S., Dias, F.O., Alves, J.M.A., Albuquerque, J.A.A., 2009. Levantamento de plantas daninhas em área rotacionada com as culturas da soja, milho e arroz irrigado no cerrado de Roraima. Revista Agro @ mbiente, 3(1), $58-63$.

Ferreira, E.A., Fernandez, A.G., Souza, C.P., Felipe, M.A., Santos, J.B., Silva, D.V., Guimarães, F.A.R., 2014. Levantamento fitossociológico de plantas daninhas em 
pastagens degradadas do Médio Vale do Rio Doce, Minas Gerais. Revista Ceres, 61(4), 502-510.

Giehl, E.L.H., Budke, J.C., 2011. Aplicação do método científico em estudos fitossociológicos no Brasil: em busca de um paradigma, in: Felfili, J.M., Eisenlohr, P.V., Melo, M.M.R.F., Andrade, L.A., Meira-Neto, J.A.A. Fitossociologia no Brasil: métodos e estudos de casos. Viçosa-MG, Universidade Federal de Viçosa, p. 23-43.

Gomes, G.L.G.C., Ibrahim, F.N., Macedo, G.L., Nobrega, L.P., Alves, E., 2010. Cadastramento fitossociológico de plantas daninhas na bananicultura. Planta Daninha, 28(1), 6168.

Guglieri-Caporal, A., Caporal, F.J.M., Pott, A., 2010. Phytosociology of sown pasture weeds under two levels of degradation in Brazilian savanna areas, Mato Grosso do Sul State, Brazil. Pesquisa Agropecuária Tropical, 40(3), 312-321.

Harpole, W.S., 2006. Resource-ratio theory and the control of invasive plants. Plant Soil, 280(1), 23-27.

Instituto Hórus de Desenvolvimento e Conservação Ambiental, 2018. Plantas daninhas do Brasil. http://www.institutohorus.org.br/inst_parceiros.htm (acessado 25 de janeiro de 2018).

Lorenzi, H. (Coord.), 2014. Manual de identificação e controle de plantas daninhas: plantio direto e convencional, sétima ed. Nova Odessa, Plantarum, p. 384.

Lorenzi, H., 2008. Plantas daninhas do Brasil: terrestres, aquáticas, parasitas e tóxicas, quarta ed. Nova Odessa, Plantarum, p. 640.

Maciel, C.D.G., Poletine, J.P., Oliveira Neto, A.M., Guerra, N., Justiniano, W., 2010. Levantamento fitossociológico de plantas daninhas em cafezal orgânico. Bragantia, 69(3), 631636.

Marques, L.J.P., Silva, M.R.M., Araújo, M.S., Lopes, G.S., Corrêa, M.J.P., Freitas, A.C.R., Muniz, F.H., 2010. Composição florística de plantas daninhas na cultura do feijão-caupi no sistema de capoeira triturada. Planta Daninha, 28 (Número Especial), 953-961.
Mi, W., Gao, Q., Sun, Y., Zhao, H., Yang, X., Guo, X., Chen, J., Wu, L., 2018. Changes in weed community with different types of nitrogen fertilizers during the fallow season. Crop Protection, 109(1), 123-127.

Moss, S.R., Storkey, J., Cussans, J.W., Perryman, S.A.M., Hewitt, M.V., 2004. The Broadbalk long-term experiment at Rothamsted: what has it told us about weeds? WeedSci, 52(5), 864-873.

Nordi, J.C., Landgraf, P.R.C., 2009. Composição florística e fitossociologia da comunidade infestante em gramado de Paspalum notatum Flügge no laboratório de botânica da Universidade de Taubaté, SP. Revista Biociências, 15(2), 106114.

Oliveira, A.C.D., Coelho, F.C., Crevelari, J.A., Silva, I.F., Rubim, R.F., 2014. Fitossociologia de plantas daninhas em monocultivo de milho e em consórcio com diferentes Fabaceae. Revista Ceres, 61(5), 643-651.

Oliveira, A.R., Freitas, S.P., 2008. Levantamento fitossociológico de plantas daninhas em áreas de produção de cana-de-açúcar. Planta Daninha, 26(1), 33-46.

Pauletti, V., 1998. Nutrientes: teores e interpretações. Campinas-SP, Fundação ABC/ Fundação Cargill, p. 59.

Roesch, L.F.W., Olivares, F.L., Passaglia, L.P.M., Selbach, P.A., Sá, E.L.S., Camargo, F.A.O., 2006. Characterization of diazotrophic bacteria associated with maize: effect of plant genotype, ontogeny and nitrogen-supply. World J Microbiol Biotechnol, 22(1), 967-974.

Sorensen, T., 1972. A method of stablishing groups of equal amplitude in plant society based on similarity of species content, in: Odum, E.P., (Ed.), Ecologia, third ed. México, Interamericana, p. 640.

Tilman, D., Wedin, D., 1991. Dynamics of nitrogen competition between successional grasses. Ecology, 73(3), 1038-1049.

Wan, L.Y., Qi, S.S., Zou, C.B., Dai, Z.C., Zhu, B., Song, Y.G., Du, D.L., 2018. Phosphorus addition reduces the competitive ability of the invasive weed Solidago canadensis under high nitrogen conditions. Flora, 240(1), 68-75. 